\title{
14. SOBRE AS NOÇÕES DE ESQUECIMENTO E MEMÓRIA NA ANALÍTICA EXISTENCIAL HEIDEGGERIANA: UM MEIO DE DISSOLUÇÃO DA SUBJETIVIDADE E DO INCONSCIENTE NA PSICANÁLISE
}

\author{
https://doi.org/10.36592/9786581110369-14
}

Marianne Conceição de Souza Girard ${ }^{1}$

\section{Resumo}

Esse trabalho se propõe a examinar as noções de esquecimento e memória na analítica existencial de Martin Heidegger a fim de contrapor sua abordagem desses fenômenos à psicanálise. Ele está dividido em duas partes: na primeira, que será mais breve, trata-se de delinear as ideias de esquecimento e memória em sentido ontológico-existencial tal como foram desenvolvidas em Ser e Tempo (1927), mostrando que, na temporalidade ekstática da compreensão, esquecimento e memória (compreendida enquanto retomada) referenciam-se ao si-mesmo do Dasein. Na segunda parte, a partir dos Seminários de Zollikon (1959-1969) iremos auscultar o que Heidegger compreendeu como esquecimento e memória cotidianos, e como pode ser elaborada uma possível tipologia do esquecimento e da memória a partir da nossa compreensão de cada modo de ser. Aqui, a referência é aos modos de ser manualidade (Zuhandenheit), ser simplesmente dado (Vorhandenheit) e os coexistentes (Mitdasein). Esses seminários são da época que Heidegger buscou, em um retorno à analítica existencial elaborada em Ser e Tempo, estabelecer diálogo com psicólogos interessados em compreender melhor seu método fenomenológico que, por acaso, foi e permanece sendo de grande importância à psicologia. Ao tratar desse tema em diálogo com o psiquiatra e psicoterapeuta Medard Boss, Heidegger procura mostrar como seu tratamento fenomenológico-hermenêutico dista radicalmente da maneira que a psicanálise se movimenta na compreensão dos fenômenos em questão. Nosso objetivo é mostrar como, a partir das noções de esquecimento e memória, Heidegger irá traçar uma distinção entre o método

\footnotetext{
${ }^{1}$ Mestra em Filosofia pela Universidade Federal de Pernambuco (UFPE). Endereço eletrônico: marigirardg@gmail.com
} 
198 | XXI Semana Acadêmica do PPG em Filosofia da PUCRS, Vol. 1

discursivo-hermenêutico e o método especulativo-explicativo, elaborando uma desconstrução da psicanálise. Como expressa Loparic (2001), nessa confrontação é intentado primordialmente uma dissolução dos conceitos de subjetividade e inconsciente.

Palavras-chave: Analítica Existencial, Esquecimento, Memória, Psicanálise

\section{Introdução}

Sabemos o quão caro foi o conceito de inconsciente na psicanálise freudiana. Toda sua experiência clínica é marcada pela dicotomia conflitante entre fenômenos conscientes e inconscientes. Ele caracteriza o inconsciente como um conjunto de representações reprimidas no sujeito cognoscente, isto é, um conjunto de representações que retemos e que não surgem ao estado consciente, embora façam parte da consciência enquanto aparelho psíquico ${ }^{2}$. Sua abordagem acerca do que significa inconsciente está diretamente relacionada com a noção de recalque (FULGÊNCIO, 2013, p. 148) (FULGÊNCIO, 2013, p. 148). Em poucas palavras, podemos dizer que esse inconsciente freudiano representa um inconsciente reprimido, cujas as representações mentais não aparecem ao estado de consciência por serem incômodas, algo que o indivíduo deseja, no fundo, omitir para si.

Heidegger, ao operar com as distinções de esquecimento e memória na sua ontologia fundamental, parece estar trabalhando com o par conceitual consciente e inconsciente, principalmente ao tratar da memória de si-mesmo, da retomada (Wiederholung), como uma espécie de tomada de consciência (HEIDEGGER, 2015. Cf. §57-§60) (HEIDEGGER, 2015. Cf. §57-§60). Mostraremos como a própria dissolução da noção de sujeito na analítica existencial heideggeriana já descarta essa possibilidade e abre margem para uma interpretação multifacetada da memória e do

\footnotetext{
2 "Segundo Freud, em Interpretação dos sonhos, o inconsciente corresponde, por um lado, a um conjunto de ideias que não são conscientes, tendo sido tornadas inconscientes para evitarem incômodo (ou dor psíquica) à consciência (ao Eu consciente) do indivíduo; por outro lado, corresponde a um sistema ou parte de um aparelho psíquico [...] trata-se de considerar que existem elementos psíquicos que não são dados à consciência, mas que existem enquanto tais, não sendo também redutíveis ao corpo. Esses elementos são representações de conteúdos cognitivos ou representações de estados mentais ou, ainda, representações carregadas de afeto e afetos como representantes de estados mentais" (FULGÊNCIO, 2013, p. 146-147) (FULGÊNCIO, 2013, p. 146-147).
} 
esquecimento desarticulada de qualquer compreensão de inconsciente enquanto inconsciente reprimido ${ }^{3}$.

\section{Temporalidade ekstática: o esquecimento e a memória existenciais}

Um dos passos iniciais de Ser e Tempo consiste em eleger um ente que teria o acesso à questão do sentido de ser. Este ente é o Dasein, "o ente que eu mesmo sou". Nota-se aqui uma peculiar designação. Por que não chamar o ente que eu mesmo sou de humano? Ou de sujeito? "Será que não estabelecemos simplesmente uma outra palavra para o mesmo ente, Dasein, em vez de sujeito? Ou será que ganhamos alguma outra coisa com essa mudança?" (HEIDEGGER, 2009, p. 76) (HEIDEGGER, 2009, p. 76). Para Heidegger, "os conceitos de 'homem', a saber: 1) ser vivo dotado de razão e 2) pessoa, personalidade, provém da experiência e visão de um mundo cujas condições objetuais nos são dadas de antemão e ocasionalmente de uma maneira determinada" (HEIDEGGER, 2013, p. 28) (HEIDEGGER, 2013, p. 28). A tradição filosófica cometeu deslizes que foram cruciais: ao passo que equivocadamente se compreende de maneira homogênea os modos de ser dos entes (isto é, enquanto simplesmente dados), também se caminha na contramão na medida em que o "sujeito", o "eu", é compreendido enquanto completamente desarraigado daquilo com que se relaciona, possuindo características (ou categorias) determinadas, isto é, simplesmente dadas 4 . Heidegger, por seu turno, irá romper com essa tradição. Já de início, distingue os modos de ser da seguinte forma: o modo de ser do ente que eu mesmo sou, Dasein, é a existência (Existenz); o de um ente disponível à mão, a manualidade (Zurhandenheit); o de uma coisa, ser simplesmente dado (Vohandenheit). E assim por diante.

Para Heidegger, também não é possível pensar ser sem nexo com o tempo. 0 Dasein é um ente temporal e toda a estrutura do seu ser só pode ser interpretada à

\footnotetext{
3 Tal raciocínio já fora desenvolvido dentro do escopo da minha dissertação Em que medida a metafísica é esquecimento histórico? defendida dia 30/08/2021.

4 "A insuficiência deste aparelho conceitual metafísico, que é substancialmente o mesmo desde Parmênides até Hegel e Nietzsche, consiste no fato de conceber o ser como Vohandenheit, como simples-presença ou realidade. É esta concepção do ser que torna impossível pensar adequadamente o fenômeno da vida e da história" (VATTIMO, 1989, p. 19) (VATTIMO, 1989, p. 19).
} 
200 | XXI Semana Acadêmica do PPG em Filosofia da PUCRS, Vol. 1

luz do tempo. Desse modo, os fenômenos do esquecimento e da memória são essencialmente temporais e são trabalhados em conjunto com a temporalidade. Iremos mostrar a partir da preleção ministrada no semestre de verão de 1927 em Marburgo/Lahn (Os Problemas Fundamentais da Fenomenologia), o que Heidegger compreende por tempo vulgar (ou tempo público) e temporalidade originária do Dasein (ou temporalidade ekstática).

A concepção de temporalidade em Heidegger não é trivial. Ele demanda muitas linhas a um exame detalhado de como Aristóteles compreendeu o tempo e como essa compreensão foi passada de mão em mão quase que indiscriminadamente. Em suas formulações principais, o conceito de tempo permaneceu inalterado durante muitas épocas. 0 tempo vulgar ${ }^{5}$ é constituído como uma sequência de agoras (HEIDEGGER, 2012, p. 375) (HEIDEGGER, 2012, p. 375); disso decorre que o tempo é visto como algo fugaz, por seu caráter de fluxo constante. Passado e futuro constituem um agora-não-mais e um agora-ainda-não, enquanto o presente é um agora fugidio. E não é só o "agora" que podemos expressar por meio dessa compreensão vulgar do tempo. Podemos também pensar no "em seguida" e no "anteriormente". Quando dizemos "em seguida" significa manifestamente uma espera por alguma coisa determinada, seja ela uma ocupação ou uma coexistência; significa, portanto, que estamos na expectativa de algo (fenômeno da expectação). Quando dizemos "anteriormente" ou "outrora", só o fazemos se retemos algo (fenômeno da retenção ${ }^{6}$ ). Por fim, quando dizemos "agora",

\footnotetext{
${ }^{5}$ Isto é, o conceito de tempo exposto por Aristóteles na Física (2009) (2009).

${ }^{6}$ Esse esquecimento relatado por Heidegger tem relação direta com o sido, e assim ele o demonstrará em Ser e Tempo. E nessa obra se tornará claro, portanto, de que maneira Heidegger articula tempo, esquecimento e memória. Essa formulação onde tempo e memória estão implicados lembra, à título de curiosidade, a análise agostiniana da memória em relação com o passado, presente e futuro. No entanto, faz-se necessário ver que Agostinho, no livro $X$ das suas Confissões, não tinha em posse a noção de "temporalidade originária do ente humano". A noção de tempo agostiniana é do início ao fim aristotélica. Também deve-se notar que Agostinho interpreta a memória à luz da reminiscência platônica (Cf. BARASH, 2008, Heidegger and the Metaphysics of memory, p. 402) (Cf. BARASH, 2008, Heidegger and the Metaphysics of memory, p. 402). Apesar de reconhecer, diferentemente de Aristóteles, que a memória tem uma relação não apenas com o passado, mas também com o presente e com o futuro, sua noção de tempo não é a temporalidade originária. Também sua preocupação não era fundamentalmente elucidar a facticidade da existência, mas muito antes como transcende-la. Ademais, a rememoração é vista como uma capacidade humana de deliberação para evocar conteúdos mnemônicos. E a memória, um sistema de armazenamento, "os vastos palácios da memória abrigam inúmeras imagens trazidas por percepções de toda espécie" (Cf. AGOSTINHO, 2017, $X$, §12) (Cf. AGOSTINHO, 2017, X, §12). À parte de algumas recauchutagens em sua tipologia da memória realizada nos parágrafos seguintes, o princípio permanece essencialmente grego: a memória
} 
nos comportamos com algo simplesmente dado e à vista, algo que se presenta, isto é, que está presente. A esse fenômeno Heidegger dá o nome de presentificação de algo. Os modos de se comportar em relação ao tempo expostos mediante os conceitos de expectação (futuro), retenção (passado) e presentificação (presente) se fundam na compreensão vulgar do tempo.

Esse tempo vulgar, que também chamamos de tempo do mundo, surge a partir da temporalidade ekstática do Dasein. Dito de outro modo: o Dasein, por ser um ente que em seu ser é temporal, pode derivar esse tempo público a partir da sua própria constituição fundamental. Dizer que a temporalidade do Dasein é ekstática significa: a temporalidade originária do Dasein "é o fora-de-si puro e simples" (HEIDEGGER, 2012, p. 388) (HEIDEGGER, 2012, p. 388). A partir de uma longa passagem da mesma obra (Cf. HEIDEGGER, 2012, p. 394) (Cf. HEIDEGGER, 2012, p. 394), visualizamos a tese de que o tempo do mundo (intratemporalidade) surge da temporalidade ekstática do Dasein. 0 encobrimento do tempo originário e da própria estrutura do tempo do mundo tem sua fundamentação no modo de ser do Dasein decadente, que se ocupa dentro do mundo e esquece de si.

No capítulo acerca Da interpretação temporal do compreender existenciário próprio e impróprio presente nos Problemas Fundamentais da Fenomenologia temos grandes avanços em comparação ao que vamos encontrar em Ser e Tempo. 0 que deste capítulo deve ser colhido são os trechos através dos quais Heidegger traz explicitamente o que ele compreende por esquecimento de si mesmo (Cf. HEIDEGGER, 2012, p. 421) (Cf. HEIDEGGER, 2012, p. 421). Ele expressa que, esquecidos, "não assumimos nós mesmos em nossa facticidade". Tudo o que somos se encontra esquecido, de alguma forma, atrás de nós mesmos.

Não assumir a si mesmo na facticidade significa, a partir de Ser e Tempo, não assumir seu poder-ser lançado (estar-lançado) mais próprio (relação com o passado ou ser-sido). 0 esquecimento não pode ser compreendido enquanto uma mera falha ou o apagamento de uma memória, mas ele é uma maneira ativa o Dasein ser-simesmo (Cf. HEIDEGGER, 2012, p. 421) (Cf. HEIDEGGER, 2012, p. 421).

é vista enquanto um sistema de armazenamento repleto de imagens e as lembranças surgem a partir de um esforço ativo que exercemos para evocá-las. Tal defesa não pode ser feita por Heidegger, pois ele não compreenderá a memória como um lugar, tampouco o esquecimento enquanto apagamento de impressões de outrora. 
202 | XXI Semana Acadêmica do PPG em Filosofia da PUCRS, Vol. 1

Podemos conferir que na segunda parte do tratado Ser e Tempo é introduzida questão da temporalidade como fio condutor para uma fundamentação ontológica originária e própria da existencialidade. A morte é um problema central na clarificação deste primeiro capítulo e deve-se levar em conta como um fenômeno que não se manifesta como um "ainda não, mas em breve sim" 7 . A morte é sempre iminente porque o Dasein é, constitutivamente, o seu ainda-não. Esse ser todo que abarca a possibilidade mais própria de ser-para-o-fim se abre a partir de uma disposição fundamental, a angústia, dando a consistência necessária para se dizer que o próprio morrer funda-se no cuidado (Sorge). A angústia é o que põe o Dasein na estranheza originária com o mundo, singularizando-o, é o que lhe assegura a consistência e que propicia o instante de decisão pelo seu ser próprio; ameaçando, assim, a tendência do Dasein ao esquecimento de si na decadência. Ela é a que proporciona a retomada do nosso poder ser mais próprio.

O Dasein decadente e esquecido não dá a oportunidade de se assumir a própria morte. Tenta-se constantemente tranquilizar os outros a respeito de suas mortes; ainda que alguém esteja de fato com uma doença muito grave, diz-se que ela "vai escapar dessa" (Cf. HEIDEGGER, 2015, p. 328-329) (Cf. HEIDEGGER, 2015, p. 328-329). Essa tranquilização, em conjunto com a tentação de encobrir a possibilidade da morte e com a alienação dessa possibilidade, fundam a maneira cotidiana que o Dasein exprime a fuga de si mesmo. A antecipação da morte, no entanto, não se caracteriza por um simples pensar na morte, mas um compreender autêntico das possibilidades como finitas ${ }^{8}$. 0 instante de decisão ${ }^{9}$ pelo reassumir a própria morte demarca em que momento estamos diante da verdade originária da existência e da retomada (memória). O decidir-se pela retomada mediante a

\footnotetext{
${ }^{7}$ Compreensão imprópria do ser-para-a-morte.

8 "Pode-se resumir a caracterização de ser que, existencialmente, se projeta para a morte em sentido próprio da seguinte forma: "o antecipar desvela para o Dasein a perdição no impessoalmente-simesmo e, embora não sustentada primariamente na preocupação das ocupações, o coloca diante da possibilidade de ser ele próprio: mas isso na liberdade para a morte que, apaixonada, fática, certa de si mesma e desembaraçada das ilusões do impessoal, se angustia" (HEIDEGGER, 2015, p. 343) (HEIDEGGER, 2015, p. 343). Aqui surge de maneira não temática o problema da liberdade. Sobre esse assunto, vejamos o que diz o intérprete Sena (2013) (2013): "O fenômeno da liberdade humana, pensado em termos ontológico-existenciais, jamais indica um ser absolutamente livre de..., porém, um ser-livre-para..., a saber: livre para um determinado mundo concreto histórico, totalidade do ente em meio à qual o ser-no-mundo está agora situado, isto é, aberto compreensivo-dispositivodiscursivamente para as coisas, de modo superavitário" (SENA, 2013, p. 137) (SENA, 2013, p. 137). ${ }^{9}$ Sobre o decidir-se próprio, (Cf. HEIDEGGER, 2015, p. 474-475) (Cf. HEIDEGGER, 2015, p. 474-475).
} 
retomada arranca o Dasein da perdição decadente da indecisão, que é sua tendência de ser e é onde o Dasein está, de modo igualmente originário, na não-verdade. Vemos aqui que o ente que nós mesmos somos de início se apresenta como o mais distante.

O esquecimento existencial do qual falamos não é um nada negativo, uma falta completa de memória. 0 esquecimento funda o Dasein e é positivamente aquilo que o move. Esquecer-se é o modo de ser(-sido, ou passado) temporal no qual de início nos encontramos e no qual podemos nos manter-se "até o fim". A recordação, por seu turno, está fundada nesse esquecimento originário, e não o contrário. Podemos sintetizar o que até então foi visto na análise da temporalidade com a seguinte passagem: "o aguardar que atualiza e esquece é uma unidade ekstática própria onde a compreensão imprópria se temporaliza em sua temporalidade" (HEIDEGGER, 2015, p. 425) (HEIDEGGER, 2015, p. 425). O modo próprio de temporalização do ser-sido, por seu turno, é chamado de retomada ${ }^{10}$.

De início e na maior parte das vezes estamos esquecidos do nosso si mesmo próprio, não ouvimos a voz da consciência que clama e conclama para uma tomada de decisão acerca do nosso próprio existir, não nos responsabilizamos por esta dívida que temos conosco. Quando estamos esquecidos, nos perdemos na agilidade do cotidiano, nas ocupações, nos compreendemos mesmo por aquilo que realizamos, por status, relações, ou seja, pelos entes que não somos. E nisso nos perdemos de vista, nos enrijecemos e colocamos sob a responsabilidade do ser-simesmo impessoal e impróprio as nossas decisões mais próprias da existência.

Conclusivamente notamos, portanto, que (1) o trabalho de uma analítica existencial inserida no contexto da ontologia fundamental consistiu numa desconstrução da ideia de sujeito, incluindo o caráter de ser-no-mundo o ente humano, Dasein; (2) que essa introdução do ser-no-mundo como caráter fundamental do Dasein trouxe uma rica abordagem ontológica sobre seus momentos estruturais; (3) que o esquecimento existencial e também a retomada (memória), enquanto possibilidades ontológicas, só podem ser vistos à luz da temporalidade ekstática do Dasein e (4) que são maneiras distintas de assumir-se no mundo (própria ou impropriamente).

\footnotetext{
${ }^{10}$ Para observar a sistematização clara entre as ekstases temporais e os modos de ser próprio e impróprio, (Cf. ESCUDERO, 2016b, §68) (Cf. ESCUDERO, 2016b, §68).
} 
204 | XXI Semana Acadêmica do PPG em Filosofia da PUCRS, Vol. 1

Essa análise dista radicalmente do que fora pensado enquanto esquecimento e memória em sentido epistemológico (sentido que Freud incorpora), pois este último tipo de investigação se direciona para a compreensão do esquecimento e da memória enquanto fenômenos exclusivamente ônticos ${ }^{11}$. Heidegger, partindo ainda da ontologia, buscará comentar também acerca do esquecimento e da memória direcionado aos outros entes mundanos e aos entes intramundanos nos seus Seminários de Zollikon.

\section{0 esquecimento e a memória em sentido cotidiano}

Nos Seminários de Zollikon, temos os diálogos entre o psicoterapeuta Medard Boss e Martin Heidegger, taquigrafados por Boss, sobre o esquecimento e a memória em sentido cotidiano. Partiremos da interpretação de Zeljko Loparic para compreendermos o que Heidegger pensou acerca desses fenômenos e como eles se relacionam com os entes mundanos e intramundanos. Loparic seguirá o fio condutor da desconstrução da psicanálise para clarificar os fenômenos de importância para este momento do trabalho.

Para Heidegger, a compreensão da psique mediante a divisão consciente/inconsciente foi um erro crasso $^{12}$. Esse pressuposto fundamental da psicanálise desemboca numa série de más compreensões acerca das estruturas do Dasein e se funda, tácita ou expressamente, na metafísica da subjetividade objetificada que fora elaborada na modernidade. Nesta época, a consciência fora

\footnotetext{
${ }^{11} \mathrm{O}$ que queremos destacar é que para a epistemologia e para as ciências particulares, como a neurociência, o esquecimento, assim como a memória, não é estudado a partir de seu fundamento no Dasein. São vistos apenas como elementos que estão "juntos ao" corpo, "dentro" do corpo, mas não são caracterizados como possibilidades ontológico-existenciais que guiam a própria lida do ente humano consigo mesmo e com os outros entes.

12 "Heidegger considera 'fatal' a distinção entre o consciente e o inconsciente não por pensar que todos os modos de ser do ser humano são, por definição, conscientes, mas por acreditar ter mostrado, em Ser e tempo, que esses modos, devido à sua estrutura ontológica, não podem ser definidos no domínio de atos mentais (representacionais). A distinção freudiana entre o consciente e o inconsciente é mal concebida: os fenômenos mencionados não são, propriamente falando, nem conscientes nem inconscientes, porque não são "atos psíquicos" ("psiquismos"), mas modos de perfazimento do elemento central da estrutura ontológica do ser humano, do ser-no-mundo. A analítica existencial de ser desconstrói a distinção-shiboleth freudiana não por ela ser absurda, mas por ser ontologicamente imprópria e, por isso, encobridora" (LOPARIC, 2001, p. 131) (LOPARIC, 2001, p. 131).
} 
tomada como a via de acesso ao "eu", às características essenciais do sujeito e seus limites. Na contemporaneidade, Freud populariza na psicologia o conceito de "inconsciente", que é o correlato opositor da consciência e que, todavia, resguardaria boa parte daquilo que fundamentalmente rege o sujeito. 0 inconsciente é postulado por necessidade de causa, embora Freud afirme que dele tem provas e que seria por essa razão que este conceito é necessário e legítimo. Loparic comenta que "Freud justificará a introdução do inconsciente [...] pela necessidade de explicar certos fenômenos observados na consciência" (LOPARIC, 2001, p. 94) (LOPARIC, 2001, p. 94), isto é, para a meta da psicanálise, tomar como dado o inconsciente é necessário, ele é o que proporciona a clarificação e resolução de distúrbios psíquicos.

Observamos que o modo como Freud compreende a facticidade está muito mais próximo de um fluxo de vivências dadas no psíquico, que manifestamente está aquém do que Heidegger compreende por facticidade ${ }^{13}$. A compreensão do sujeito enquanto essencialmente psíquico e, por conseguinte, a compreensão do psíquico enquanto sequência de vivências não pode fornecer satisfatoriamente a estrutura fenomenal da facticidade do Dasein. Com isso, não queremos defender uma negação do fenômeno da consciência, mas apenas demonstrar que (1) ela não é ontologicamente fundamental e que (2) os conceitos fundamentais das ciências particulares não devem possuir suas determinações a partir desse fenômeno nãofundamental que é a consciência enquanto aparelho psíquico (Cf. LOPARIC, 2001, p. 105) (Cf. LOPARIC, 2001, p. 105).

Da mesma forma que a consciência tem correspondência direta em relação a memória na psicologia freudiana, o inconsciente tem intrínseca relação com o esquecimento. Freud concebe o esquecimento enquanto um processo psíquico que pode ocorrer tanto voluntária quanto involuntariamente por meio da extinção,

\footnotetext{
13 "Qual é o modo de facticidade que a psicologia empírica de Freud atribui aos fenômenos que estuda? A resposta é: o de um 'psiquismo' (das Psychische). Para Freud, o psiquismo é um conjunto de fenômenos ou de processos mentais, conscientes ou inconscientes, de um indivíduo ou de um grupo de indivíduos, sediados em ou produzidos por uma psique (Seele). Os processos psíquicos são ditos mentais, no sentido de serem atos representacionais carregados afetivamente. [...] 0 psiquismo é, além disso, um processo natural e a psicologia, uma ciência natural, que, como qualquer outra disciplina elaborada no paradigma galileano, assume o pressuposto ontológico de que os fenômenos psíquicos obedecem às relações espaço-temporais e causais externas, constituindo 'correntes' ou 'cadeias', cujos elos são atos mentais singulares" (LOPARIC, 2001, p. 97) (LOPARIC, 2001, p. 97).
} 
206 | XXI Semana Acadêmica do PPG em Filosofia da PUCRS, Vol. 1

repressão e atrofia ou apagamento de memórias que não são utilizadas, correspondente ao esquecimento real (Cf. IZQUIERDO; BEVILAQUA; CAMMAROTA, 2006, p. 289-296) (Cf. IZQUIERDO; BEVILAQUA; CAMMAROTA, 2006, p. 289-296). Essa introdução sucinta dos pressupostos da psicanálise freudiana se mostra muito pertinente para demarcar a posição heideggeriana em relação aos fenômenos aqui em questão.

Para ilustrar de que maneira se expressa linguisticamente o método especulativo-explicativo em contraposição ao discurso fenomenológico-descritivo auscultaremos algumas passagens que Loparic traz em seu texto. É importante frisar que "em Freud, toda compreensão é, ao mesmo tempo, explicação: o que se compreende e interpreta é a causa de um sintoma. As interpretações psicanalíticas são explicações causais do sentido dos sintomas" (LOPARIC, 2001, p. 98) (LOPARIC, 2001, p. 98). O exemplo dado por Boss a respeito de como a teoria psicanalítica interpretaria o esquecimento relaciona-se perfeitamente com essa ideia de explicação ou busca de causas: "de acordo com a teoria psicanalítica, no caso de [uma mulher] esquecer, por exemplo, uma bolsa, ao sair do quarto de uma pessoa conhecida, expressa-se o desejo inconsciente de poder voltar àquele lugar" (LOPARIC, 2001, p. 112) (LOPARIC, 2001, p. 112). Heidegger, por seu turno, diria que não há intenção inconsciente no ato de esquecer a bolsa, mas sim que porque o homem o qual a mulher visita não lhe é indiferente que, mesmo ao ir embora, lá ela permanece. A bolsa não é intencionalmente, de maneira velada, deixada lá; para a mulher, que estava tão junto ao seu amante, a bolsa sequer estava lá. Isso aponta para o fato de que a abordagem fenomenológica não busca conhecimento de causa, mas busca descrever os fenômenos tal como eles se mostram. $O$ fenômeno cotidiano do esquecimento, em Freud, se dá por mera relação causal e tem seu fundamento no inconsciente, enquanto que, para Heidegger, não podemos esperar atingir o que seria esquecimento cotidiano se fundamentamos tal visão a partir de uma metafísica que objetifica o Dasein e a partir de relações causais que, para além de não configurarem o modo mais originário de acesso ao fenômeno do esquecimento, não são minimamente comprováveis.

O que está em xeque aqui não é a eficácia da psicanálise ou o seu estatuto científico, mas os pressupostos da psicologia acerca do que seria o humano, a 
psique - e sua divisão em consciente, pré-consciente e inconsciente - doença e saúde. $\mathrm{O}$ conteúdo inconsciente, velado, e, de certa maneira, esquecido, pode vir à tona sem que, no entanto, se tenha tornado mais claro o seu fundamento - e fundamento aqui não se confunde com a causa ou a causa primeira. A rememoração de eventos ônticos ou o trazer à superfície de um desejo reprimido não podem ainda dar conta do esquecimento fundante do Dasein que caracterizamos como esquecimento existencial ou esquecimento de si. Esse não pode ser superado mediante uma análise de seu inconsciente, mas apenas com o despertar de um afeto fundamental - a disposição afetiva da angústia é a que ganha destaque em Ser e Tempo. Já o esquecimento e a memória em sentido cotidiano são vistos, segundo Heidegger, como uma derivação do esquecimento originário (Cf. HEIDEGGER, 2015, p. 425) (Cf. HEIDEGGER, 2015, p. 425).

0 inconsciente constitui um conceito tão obscuro quanto o seu correlato (consciente); mas não somente essa caracterização nebulosa da psique pode ser brutal para a formação de uma ciência rigorosa como pode encobrir a própria constituição ontológica do Dasein. Postular o inconsciente mediante a justificativa de que "funciona" ainda não esclarece suficientemente para quê ele funciona; toda a ordem de conceitos que o rodeia (como o par doença/saúde) se orienta ainda por uma atitude natural para com os entes, isto é, os toma como dados, fato bruto no mundo, e o ente a ser perscrutado, o Dasein, permanece compreendido como simplesmente dado, subjetividade objetificada, e não é vislumbrado a partir do seu próprio modo de ser que é a existência.

Não podemos dizer, contudo, que a psicologia não tem uma ontologia fundante. O que se exprime é, todavia, mais desastroso que isso: que há uma ontologia cristalizada e não suficientemente clara que funda todos os conceitos da psicanálise e que, por conseguinte, vela a própria estrutura existencial do Dasein (como ser-no-mundo, ser-junto-a, ser-com, ser-si-mesmo).

Por fim, numa caracterização crua e assistemática que conferimos a partir dos Seminários de Zollikon, no capítulo Do Esquecimento (Cf. HEIDEGGER, 2017, p. 176177) (Cf. HEIDEGGER, 2017, p. 176-177), observamos que há várias maneiras de conceber o esquecimento cotidiano - que depende, sobretudo, de para que tipo de ente ele está orientado, de seu contexto enquanto ser-no-mundo. Heidegger traz à 
208 | XXI Semana Acadêmica do PPG em Filosofia da PUCRS, Vol. 1

tona dois destes tipos possíveis de esquecimento: o esquecimento do ente disponível à mão (Zuhandenheit) como privação da lembrança de algo (memória como lembrança) e do ser-simplesmente-dado (Vorhandenheit) como privação da retenção (memória como retenção). A diferença que se estabelece, a partir de certo esforço interpretativo, pode ser a seguinte: o esquecer de um casaco ${ }^{14}$ para o frio é uma falha pessoal, talvez por estar ocupada com outras atividades. Mas, dentro da nossa conjuntura, faria sentido lembrar, uma vez que é necessário para que não se passe frio quando fizer frio. Já o escapar de um nome ${ }^{15}$ de uma pessoa que foi introduzida numa festa e nunca mais apareceu, por exemplo, tem o caráter de privação de um simples reter, pois essa informação estaria descontextualizada da totalidade de uma rede pessoal de significância.

Na seção Do Recordar, Heidegger explicita que:

Recordar é tornar presente algo que passou como alguma coisa experienciada por mim há certo tempo. Quando me ocorre um nome esquecido, isso não é uma recordação. Só seria uma recordação se o nome me ocorresse como algo que eu ouvi ou aprendi na época. Mas quando o nome esquecido me ocorre meramente como nome, então isso é somente um tornar presente de novo. (HEIDEGGER, 2017, p. 178) (HEIDEGGER, 2017, p. 178).

Ou seja, a recordação não poderia ser recordação de uma coisa simplesmente dada, desafigurada de seu contexto, mas apenas se configura como recordação a memória que temos de algo que diz respeito ao nosso ser. Um simples "tornar presente" de um nome retido de outrora não é uma recordação strictu sensu, pois, de acordo com o fenomenólogo, não traz à tona nada que tenha sentido para o Dasein enquanto ser-no-mundo.

Pensando em uma tipologia do esquecimento e memória cotidianos que consiga abarcar o Dasein em sua cotidianidade, podemos concluir que, segundo Heidegger: (1) foi preciso um outro tipo de discurso, que dista do expeculativoexplicativo (particular das ciências), para acessarmos os fenômenos analisados, (2)

${ }^{14}$ Caracterizado por ser-junto-a, isto é: um objeto que serve-para dentro da minha rede de significância.

${ }^{15}$ Neste contexto, um ser-simplesmente dado. 
que há diversos tipos de esquecimento e também de memória cotidianos, a saber, a lembrança, a retenção e a recordação. 0 esquecimento configurado por um não reter refere-se a entes simplesmente dados, o esquecimento configurado por um não lembrar refere-se a entes intramundanos - utensílios, equipamentos ou dispositivos, por exemplo - e o esquecimento configurado por um não recordar refere-se a entes mundanos - outros entes coexistentes - e acontecimentos que estão na nossa rede de significância enquanto somos estruturalmente ser-no-mundo.

\section{Tabela - Tipologia da Memória e do Esquecimento cotidianos}

\begin{tabular}{|c|c|c|c|}
\hline \multicolumn{2}{|c|}{ MEMÓRIA } & & \\
\hline \multirow{2}{*}{$\begin{array}{l}\text { MANUALIDA } \\
\text { DE } \\
\text { (ZUHANDEN } \\
\text { HEIT) }\end{array}$} & \multirow[t]{2}{*}{$\begin{array}{l}\text { Lembrança } \\
\text { (Andenken) }\end{array}$} & \multicolumn{2}{|c|}{ ESQUECIMENTO } \\
\hline & & MANUALIDADE & Privação da \\
\hline \multirow{2}{*}{$\begin{array}{c}\text { SER- } \\
\text { SIMPLESME } \\
\text { NTE-DADO } \\
\text { (VORHANDE } \\
\text { NHEIT) }\end{array}$} & \multirow{2}{*}{$\begin{array}{l}\text { Retenção } \\
\text { (Behalten) }\end{array}$} & $\begin{array}{c}\text { (ZUHANDENHEI } \\
T)\end{array}$ & lembrança \\
\hline & & $\begin{array}{c}\text { SER- } \\
\text { SIMPLESMENTE } \\
\text {-DADO }\end{array}$ & $\begin{array}{l}\text { Privação da } \\
\text { retenção }\end{array}$ \\
\hline \multirow{2}{*}{$\begin{array}{l}\text { COEXISTENT } \\
\text { ES } \\
\text { (MITDASEIN) }\end{array}$} & \multirow{2}{*}{$\begin{array}{l}\text { Recordação } \\
\text { (Erinnern) }\end{array}$} & EIT) & \\
\hline & & $\begin{array}{c}\text { COEXISTENTES } \\
(M T T D A S E I N)\end{array}$ & $\begin{array}{l}\text { Privação da } \\
\text { recordação }\end{array}$ \\
\hline
\end{tabular}

Para a elaboração da tabela consultamos o original em alemão (1987) (1987) e tradução em inglês (2001) (2001). Assim como no português, a versão original e a versão em inglês possuem expressões de grafia e significado distintas para cada referente modo de ser. No inglês, as traduções são respectivamente recalling, retaining e remember. No primeiro sentido (lembrança), podemos interpretar a atitude de lembrar como uma atitude relacionada a "contar com" alguma coisa. Heidegger mesmo utiliza o exemplo da memória de que preciso do guarda-chuva 
210 | XXI Semana Acadêmica do PPG em Filosofia da PUCRS, Vol. 1

para-algo como uma espécie de lembrança. Resguarda, portanto, o caráter de utilidade. A retenção pode ser interpretada como um simples "manter", possuir consigo, mas sem utilidade ou sentido determinados. Já a recordação, como sabemos, "trazer de volta ao coração", implica uma relação mais explícita com os coexistentes, onde é patente a remissão a afetos "não-cinzentos". Ainda que no português utilizemos de maneira intercambiável as palavras "lembrança" e "recordação", podemos notar que utilizamos também a palavra "lembrança" para nos referir a um objeto ou artifício que estimule a recordação. Um instrumento que, portanto, possui utilidade. Já a recordação utilizamos apenas no sentido de "trazer de volta" algo do sido.

\section{Conclusão}

Embora não haja literatura secundária pertinente em torno do tema, a abordagem do ente humano na filosofia heideggeriana que tematiza explicitamente o fenômeno do esquecimento se mostra muito profícua para que possamos conceber tal fenômeno como um problema rigorosamente ontológico. No esquecimento existencial (si-mesmo impróprio) é sustentado que o Dasein se esquece de que ele é o fundamento de seu próprio ser e que precisa se decidir por dar - ou, dito de maneira mais precisa, criar - para ele um sentido. É um esquecimento originário, que precede a memória (retomada do si-mesmo próprio).

O esquecimento e a memória referente aos outros entes - e não ao si-mesmo do Dasein, - os quais nos referimos como fenômenos cotidianos por se relacionarem com a facticidade do Dasein -, se expressam como uma crítica à noção tradicional de subjetividade e nos mostra como esses fenômenos podem ser interpretados caso a caso, dependendo da rede referencial do Dasein. O fenômeno cotidiano do esquecimento é interpretado por Heidegger como oriundo do esquecimento existencial originário. Essa formulação é, definitivamente, muito curiosa e rica.

Com essa exposição, esperamos mostrar que é possível visualizar na ontologia fundamental heideggeriana uma crítica também ao inconsciente por intermédio da sua formulação acerca do que podemos compreender por Dasein, estruturas fundamentais, tempo, esquecimento e memória. 


\section{Referências}

AGOSTINHO, S. Confissões. Tradução: Lorenzo Mammì. São Paulo: Penguins Companhia das Letras, 2017.

ARISTÓTELES. Física I-II. Tradução: Lucas Angioni. São Paulo: Editora da Unicamp, 2009.

BARASH, J. A. Heidegger and the Metaphysics of Memory. Studia

Phænomenologica, v. 8, p. 401-409, 2008. Disponível em:

$<$ https://www.researchgate.net/publication/269799381_Heidegger_and_the_Metap hysics_of_Memory> Acesso em: 15 de agosto de 2021 .

ESCUDERO, J. A. Guía de lectura de Ser e Tiempo Vol. 2. Barcelona, España: Herder, 2016.

FULGÊNCIO, L. Ampliação winnicottiana da noção freudiana de inconsciente. Psicologia USP, v. 24(1), p. 143-164, 2013. Disponível em:

$<$ https://www.scielo.br/j/pusp/a/9VBQ6gvzWwpRGYjjhcXknCy/?lang=pt\&format=p df> Acesso em: 15 de agosto de 2021.

HEIDEGGER, M. Introdução à filosofia. Tradução: Marco Antônio Casanova. São Paulo: Martins Fontes, 2009.

HEIDEGGER, M. Ontologia: hermenêutica da facticidade. Tradução: Renato Kirchner. $2^{\mathrm{a} e d}$. Petrópolis, RJ: Vozes, 2013. (Coleção textos filosóficos).

HEIDEGGER, M. Os problemas fundamentais da fenomenologia. Tradução: Marco Antônio Casanova. 2ªed. Petrópolis, RJ: Vozes, 2012.

HEIDEGGER, M. Seminários de Zollikon: protocolos, diálogos, cartas. Tradução: Gabriella Arnhold Prado Maria de Fátima. 3ªed. São Paulo: Escuta, 2017.

HEIDEGGER, M. Ser e Tempo. Tradução: Márcia Sá Cavalcante Schuback. $10^{\text {aed. }}$ Petrópolis, RJ: Vozes, 2015.

HEIDEGGER, M. Zollikon Seminars: Protocols - Conversations - Letters. Tradução: Franz Mayr and Richard Askay. Evanston, Illinois: Northwestern University Press, 2001.

HEIDEGGER, M.; BOSS, M. Zollikoner Seminare: Protokolle, Gespräche, Briefe. Frankfurt am Main: V. Klostermann, 1987.

IZQUIERDO, I.; BEVILAQUA, L. R. M.; CAMMAROTA, M. A arte de esquecer. Estudos Avançados, v. 20, n. 58, 2006. Disponível em:

<https://www.scielo.br/j/ea/a/5N7GQLBShWJ4ytCL5JRXv8Q/?lang=pt\&format=pdf > Acesso em: 15 de agosto de 2021 
212 | XXI Semana Acadêmica do PPG em Filosofia da PUCRS, Vol. 1

LOPARIC, Z. Além do inconsciente: sobre a desconstrução heideggeriana da psicanálise. Natureza Humana, v. 3, n. 1, p. 91-140, 2001. Disponível em:

<http://pepsic.bvsalud.org/pdf/nh/v3n1/v3n1a04.pdf> Acesso em: 15 de agosto de 2021.

SENA, S. Mundano, demasiado mundano: Filosofia como problema da liberdade a partir de Heidegger e Aristóteles. Ekstasis: revista de fenomenologia e hermenêutica, v. 2, n. 2, p. 111-141, 2013. Disponível em: < https://www.epublicacoes.uerj.br/index.php/Ekstasis/article/view/8185> Acesso em: 15 de agosto de 2021.

VATTIMO, G. Introdução a Heidegger. Tradução: João Gama. Rio de Janeiro: Edições 70, 1989. 